\title{
MOLECULAR IDENTIFICATION AND ANTIBIOGRAM PROFILES OF ESCHERICHIA COLI ISOLATED FROM APPARENTLY HEALTHY AND DIARRHEIC GOATS
}

\author{
F. Begum, M. M. Islam, M. Sohidullah, S. M. L. Kabir, M. Islam and M. T. Rahman* \\ Department of Microbiology and Hygiene, Faculty of Veterinary Science, Bangladesh Agricultural University, \\ Mymensingh-2202, Bangladesh
}

\begin{abstract}
The present study was designed for the cultural, biochemical characterization and molecular detection of E. coli from apparently healthy and diarrheic goats in and around BAU campus including their antibiogram study. A total of 50 fecal samples were collected among which 13 originated from diarrheic goat and 37 from apparently healthy goats. Out of 50 samples, 35 were found positive for E. coli i.e., overall $70 \%$ occurrence. Occurrences of E. coli from diarrheic and apparently healthy goats were $92 \%$ and $62 \%$ respectively. Occurrences were $60 \%, 80 \%$ and $70 \%$ in case of BAU Goat Farm, Veterinary Teaching Hospital and Boyra respectively. On age basis 93\%, 54\%, 66\% and 54\% samples originated from 6 months, 7-12 months, 13-18 months and 19 months aged goats were found positive respectively. Occurrences of $E$. coli on the basis of sex were $78 \%$ for male and $62 \%$ for female. In case of breed, the occurrences were $69 \%$ in Black Bengal and $100 \%$ in for Jamunapari. Molecular detection was done by PCR and 13 out of 20 isolates tested gave the bands at the 585 bp specific for $E$. coli $16 \mathrm{~S}$ rRNA gene. All the isolates (100\%) were found sensitive to ciprofloxacin and norfloxacin; $100 \%$ and $35 \%$ were intermediately resistant to tetracycline and gentamicin respectively and $25 \%$ isolates were resistant to streptomycin. Ciprofloxacin and norfloxacin were found to be the best choice of antibiotics for the treatment of colibacillosis in goats in the study area.
\end{abstract}

Key words: E. coli, goats, occurrence, PCR, antibiogram profile

\section{INTRODUCTION}

Livestock population in Bangladesh is currently estimated to comprise 25.7 million cattle, 0.83 million buffaloes, 14.8 million goats, 1.9 million sheep, 118.7 million chicken and 34.1 million ducks (Banglapedia, 2015). Among livestock population goats are known as poor person's bank or poor family's insurance policy and distributed mainly with landless and marginal farmers, but now-a-days the commercial goat farming is also gaining much importance.

The major loss faced by the goat farmers is in terms of mortality and morbidity of young animals and is mainly due to diarrhea which is a complex interaction of etiological, immunological, and managemental factors. Escherichia coli play an important role in causing diarrhea and other infectious diseases in goats. Pathogenicity of E. coli strains are due to the presence of one or more virulence factors including invasiveness factors like invasins, heat labile, heat stable enterotoxins, verotoxins and colonization factors or adhesins (Kaper et al., 2004). Pathogenic E. coli are divided into two types- Enteropathogenic E. coli and Uropathogenic E. coli. Enteropathogenic E. coil is further grouped into Enterotoxigenic E. coli (ETEC), Enteropathogenic E. coli (EPEC), Enteroinvasive E. coli (EIEC), Enteroaggregative E. coli (EAggEC), Enterohemorrhagic E. coli (EHEC) which are responsible for causing diarrhea or related illness (Islam et al., 2016).

In case of diarrhea in goat or other animals, the precise role of $E$. coli is not clear because this organism is part of normal intestinal flora in both healthy and diseased animals. At least three explanations for the presence of $E$. coli in the gut of diarrheic animals are possible: (a) E. coli isolate may be a part of normal intestinal flora and the diarrhea has another etiology. (b) The mechanism responsible for infection creates an imbalance in the digestive system that enables E. coli to grow and perhaps to secondary diarrhea. (c) E. coli alone is responsible for causing diarrhea (Radostits et al., 2000). The economic aspect of diarrheal diseases in goats and their mortality and morbidity is a matter of great concern to the livestock owners. It can be controlled following the maintenance of strict hygienic and sanitary measures in addition to antibiotic therapy.

\footnotetext{
*Corresponding e-mail address: tanvirahman @bau.edu.bd
} 


\section{F. Begum and others}

Antibiotics are widely used for the treatment of diarrhea in goats. Incomplete course of treatment and continuous indiscriminate use of antibacterial drugs against diarrheal infection of man and animal might have influenced to produce a new generation of virulent and resistant type of bacteria (Marshall et al., 1990). Escherichia coli has become resistant to many antimicrobials through the acquisition of mobile drug resistance genes and the incidence of multiple antibiotic resistant E. coli strains has been increasing. Different parameters including the isolation, identification, vaccination, plasmid profiling, antibiotic sensitivity and epidemiological investigation of E. coli of different species were studied in Bangladesh by Islam et al. (2008), Nazir et al. (2005); Abdullah et al. (2010), Islam et al. (2016) and Gupta et al. (2016). However, as far as we know molecular detection and antibiogram study of E. coli from healthy and diarrheic goats in BAU and surrounding areas recently were not systematically focused. Therefore, the present study was performed to isolate and molecular detection of E. coli inhabiting in feces of goats and to assess antibiogram profiles of the isolated E. coli.

\section{MATERIALS AND METHODS}

This research work was conducted during the period of January, 2016 to May, 2016 in the Bacteriology Laboratory of the Department of Microbiology and Hygiene, Bangladesh Agricultural University (BAU), Mymensingh.

\section{Collection of samples}

A total of 50 rectal swab samples were aseptically collected from the diarrhoeic goats of BAU, Mymensingh and surrounding area. Among 50 samples, 20 originated from BAU Goat Farm (19 apparently healthy and one 1 diarrheic goat), 20 from Veterinary Teaching Hospital, BAU (10 apparently healthy and 10 diarrheic goats) and 10 from Boyra, Mymensingh (8 apparently healthy and 2 diarrheic goats). After collection, the samples were transported to the Bacteriology, Department of Microbiology and Hygiene, BAU as soon as possible for the bacteriological examinations and further characterization.

\section{Isolation of $E$. coli}

The isolation and identification of $E$. coli were performed according to the method described by Cowan (1985).The isolated bacteria was initially identified as E. coli by observing their cultural characteristics, morphology by Gram's stain, biochemical tests, motility test and finally confirmed by PCR through amplification of E. coli specific 16S RNA gene.

\section{Molecular detection of $E$. coli by PCR targeting $E$. coli 16S rRNA gene}

Extraction of DNA from the E. coli was carried out by conventional boiling and rapid cooling method (Medici et al., 2003). In brief $200 \mu \mathrm{l}$ deionized water was taken into an eppendorf tube, a pure colony of E. coli from nutrient agar was mixed with the deionized water. The tube was then transferred to boiling water for 10 minutes then it was immediately taken to the icebox for cold shock about 10 minutes. After cold shock centrifugation at $10,000 \mathrm{rpm}$ for 10 minutes was done. The supernatant was collected which was used as template DNA. Details of the oligonucleotide primers used for the amplification of $16 \mathrm{~S}$ rRNA gene of E. coli as shown in Table 1. The PCR reaction mixture $(25 \mu \mathrm{l})$ for $E$. coli was prepared using $12.5 \mu 1$ master mixture (Promega, USA), 10 pmol primer (Bioneer, South Korea) of each, $5 \mu 1$ DNA template and $5.5 \mu$ l nuclease free water. The cycling conditions consisted of initial denaturation for 5 minutes at $95^{\circ} \mathrm{C}$, followed by 30 cycles of denaturation at $94^{\circ} \mathrm{C}$ for 0.5 minutes, annealing at $58^{\circ} \mathrm{C}$ for 1 minute and extension at $72^{\circ} \mathrm{C}$ for 1 minute. The final extension was conducted at $72^{\circ} \mathrm{C}$ for 10 minutes. Amplification was performed in a thermal cycler (Astec, Japan). The amplified products were electrophoresed into $1.5 \%$ agarose (Sigma-Aldrich, USA) gel at 80 volt for 45 minutes and then visualization was done under Gel doc/UV trans-illuminator (BioRad).100 bp DNA size marker (Promega, USA) was used. 
Molecular identification and antibiogram profiles of goats

Table 1. Primer sequence, target gene and predicted size of amplified product of $E$. coli specific 16S rRNA

\begin{tabular}{llcll}
\hline Primer name & Sequence $\left(5^{\prime}-3^{\prime}\right)$ & Target gene & Amplicon size (bp) & Reference \\
\hline ECO-1 & GACCATCGGTTAGTTCACAGA & $\begin{array}{c}\text { E. coli } \\
\text { 16S rRNA }\end{array}$ & 585 & $\begin{array}{l}\text { Schippa et } \\
\text { al.(2010) }\end{array}$ \\
ECO-2 & CACACGCTGACGCTGACCA & & & \\
\hline
\end{tabular}

\section{Antibiogram Study}

Antibiogram study was performed by employing the Kirby-Bauer disc diffusion method (Bauer et al., 1959) using five different commercially available antibiotic discs (HiMedia, India and Oxoid Ltd., England) on Mueller-Hinton agar (HiMedia, India) to assess the susceptibility and resistance pattern of the E. coli isolates. The selected antibiotics used were ciprofloxacin $(5 \mu \mathrm{g} / \mathrm{disc})$, gentamicin $(10 \mu \mathrm{g} / \mathrm{disc})$, norfloxacin $(10 \mu \mathrm{g} / \mathrm{disc})$, streptomycin $(10 \mu \mathrm{g} / \mathrm{disc})$, and tetracycline $(30 \mu \mathrm{g} / \mathrm{disc})$. The interpretation on susceptibility was done according to the guidelines of Clinical and Laboratory Standards Institute (CLSI, 2012). In this study, multidrug resistant $E$. coli was identified by considering resistant to 2 or more drugs.

\section{RESULTS AND DISCUSSION}

Out of 50 rectal swab samples 35 were found positive for E. coli. The Gram negative small rod shaped organisms produced circular, smooth, colorless colony on NA. All the isolates produced greenish-black colonies with metallic sheen on EMB agar and bright pink or red colored colonies on MC agar as described by Merchant and Packer (1967). All the E. coli isolates were found positive to motility test and fermented the five basic sugars with the production of acid and gas. Among the 35 E. coli 20 were selected for molecular detection by PCR targeting 16S rRNA gene of E. coli (amplicon size $585 \mathrm{bp}$ ). Among them 13 isolates were found E. coli positive by PCR.

The occurrence of $E$. coli (Table 2) from diarrheic goats was $92 \%(n=23 / 37)$ and apparently healthy goats was $62 \%(n=12 / 13)$. Islam et al. (2016) also observed higher rate of presence of $E$. coli in diarrhoeic goat than healthy goat. In BAU goat farm the prevalence of E. coli was $60 \%(n=12 / 20), 80 \%(n=16 / 20)$ in Veterinary teaching hospital and $70 \%(n=7 / 10)$ in Boyra. The prevalence of E. coli was $93 \%(n=14 / 15)$ in 6 months aged goats, $54 \%(n=7 / 12)$ in 7-12 months aged goats, $66 \%(n=8 / 11)$ in $13-18$ months aged goats and $54 \%(n=6 / 12)$ in 19 months aged goats. In male goats the prevalence of $E$. coli was $78 \%(n=18 / 23)$ and $62 \%(n=17 / 27)$ in female goats. In case of breed the prevalence of E. coli was $69 \%(n=34 / 49)$ in Black Bengal goats and $100 \%(n=1 / 1)$ in Jamunapari goat. Islam et al. (2016) detected 52\% fecal sample positive for E. coli in goat rectal swab in Cox's Bazar area. Among the isolated E. coli many could be pathogenic. Islam et al. (2008) detected occurrence of $10 \%$ STEC in rectal swab of goat collected from slaughter house in Bangladesh. These observed variations in the occurrence of $E$. coli in different categories of goat population in our study could be due to the different hygiene and management practice of the goat owners. 


\section{F. Begum and others}

Table 2. Occurrence of E. coli on the basis of different parameters

\begin{tabular}{|c|c|c|c|c|}
\hline \multicolumn{2}{|c|}{ parameter } & $\begin{array}{c}\text { No. of samples } \\
\text { analyzed }\end{array}$ & $\begin{array}{l}\text { No. of samples found positive } \\
\text { for } E \text {. coli }\end{array}$ & Prevalence (\%) \\
\hline \multirow{3}{*}{ Health status } & $\begin{array}{l}\text { Apparently } \\
\text { Healthy }\end{array}$ & 37 & 23 & 62 \\
\hline & Diarrheic & 13 & 12 & 92 \\
\hline & Total & 50 & 35 & 70 \\
\hline \multirow{4}{*}{ Location } & BAU Goat farm & 20 & 12 & 60 \\
\hline & VTH & 20 & 16 & 80 \\
\hline & Boyra & 10 & 7 & 70 \\
\hline & Total & 50 & 35 & 70 \\
\hline \multirow{5}{*}{ Age } & $\leq 6$ months & 15 & 14 & 93 \\
\hline & $7-12$ months & 12 & 7 & 58 \\
\hline & 13-18 months & 11 & 8 & 66 \\
\hline & $\geq 19$ months & 12 & 6 & 54 \\
\hline & Total & 50 & 35 & 70 \\
\hline \multirow{3}{*}{ Sex } & Male & 23 & 18 & 78 \\
\hline & Female & 27 & 17 & 62 \\
\hline & Total & 50 & 35 & 70 \\
\hline \multirow{3}{*}{ Breed } & Black Bengal & 49 & 34 & 69 \\
\hline & Jamunapuri & 1 & 1 & 100 \\
\hline & Total & 50 & 35 & 70 \\
\hline
\end{tabular}

*VTH= Veterinary Teaching Hospital

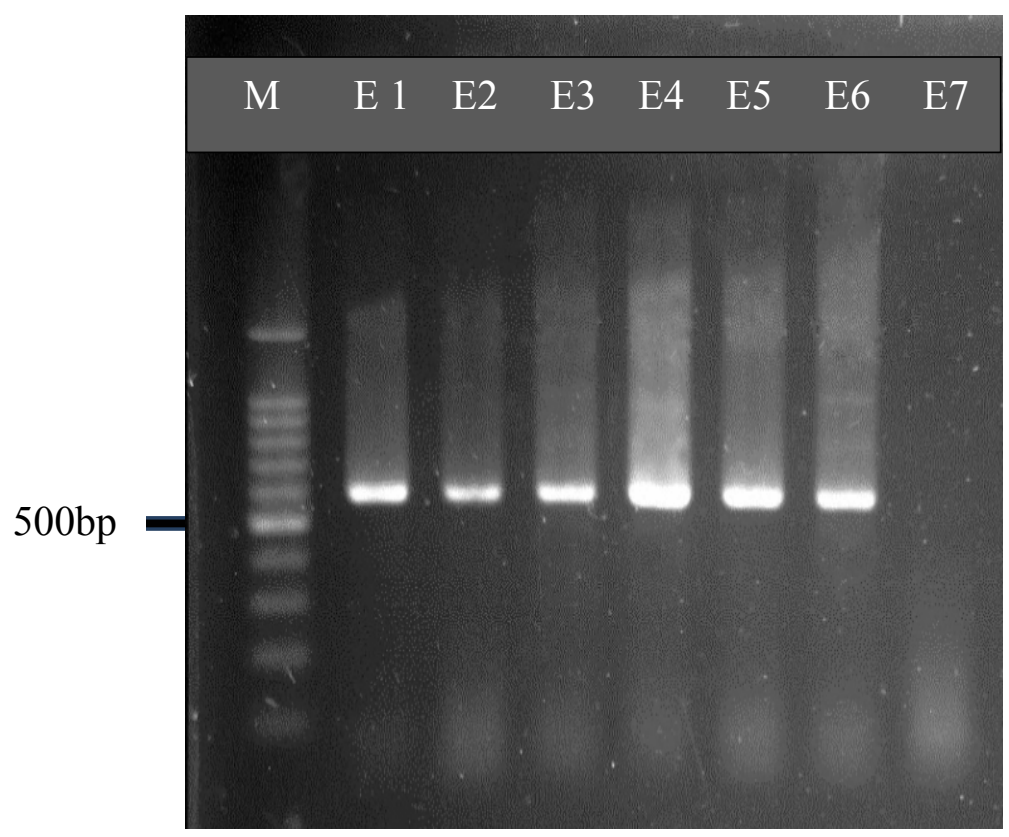

Figure 1. PCR for E. coli 16S rRNA gene. Lane M: 100 bp DNA Marker; Lanes E1-E5 isolated E. coli, E6 positive control and E7 negative control. Expected amplicon size is $585 \mathrm{bp}$. 
A total of 20 randomly selected isolates were subjected to the antibiogram study. The results of antibiogram study are presented in Table 3 and 4. Among them 10 isolates were taken from apparently healthy goats and 10 were taken from diarrheic goats. On the basis of health status, isolated E. coli both from apparently healthy and diarrheic goats were found $100 \%$ sensitive to ciprofloxacin and norfloxacin; $20 \%$ were resistant to tetracycline and $80 \%$ were intermediately resistant to tetracycline. From apparently healthy goats $30 \%$ isolates were found intermediately resistant to gentamicin and $40 \%$ isolates were resistant to streptomycin. From diarrheic goats $40 \%$ were found intermediately resistant to gentamicin and $10 \%$ isolates were resistant to streptomycin. Overall, $100 \%$ isolates were found sensitive to ciprofloxacin and norfloxacin; $90 \%$ and $35 \%$ were intermediately resistant to tetracycline and gentamicin respectively; $25 \%$ isolates were resistant to streptomycin and $2 \%$ isolates were resistant to tetracycline. In this study, E. coli isolated from goats were found highly sensitive to ciprofloxacin. Similar type of antibiogram profile of $E$. coli originating from various sources has earlier been reported by Nazir et al. (2005). Among the E. coli studied, 2 isolates were found multidrug resistant i.e., resistant to streptomycin and tetracycline. Islam et al. (2016) also reported the occurrence of multidrug resistant $E$. coli in goat population in Bangladesh.

Table 3. Antibiogram profiles of the isolated E. coli from apparently healthy and diarrheic goats

\begin{tabular}{ccccccc}
\hline \multirow{2}{*}{$\begin{array}{c}\text { Sources of } E \text {. coli } \\
\text { Isolates }\end{array}$} & \multicolumn{2}{c}{ Resistant } & \multicolumn{2}{c}{ Intermediate } & \multicolumn{2}{c}{ Sensitive } \\
& Antibiotic & No. (\%) & Antibiotic & N0. (\%) & Antibiotic & No. (\%) \\
\hline $\begin{array}{c}\text { Apparently } \\
\text { Healthy } \\
(\mathrm{n}=10)\end{array}$ & S & $4(40 \%)$ & $\mathrm{S}$ & $0(0 \%)$ & $\mathrm{S}$ & $6(60 \%)$ \\
& $\mathrm{GEN}$ & $0(0 \%)$ & GEN & $3(30 \%)$ & GEN & $7(70 \%)$ \\
& NOR & $0(0 \%)$ & NOR & $0(0 \%)$ & NOR & $10(100 \%)$ \\
& TE & $0(0 \%)$ & TE & $10(100 \%)$ & TE & $0(0 \%)$ \\
Diarrheic & S & $1(10 \%)$ & S & $0(0 \%)$ & S & $9(90 \%)$ \\
$(\mathrm{n}=10)$ & GEN & $0(0 \%)$ & GEN & $4(40 \%)$ & GEN & $6(60 \%)$ \\
& CIP & $0(0 \%)$ & CIP & $0(0 \%)$ & CIP & $10(100 \%)$ \\
& NOR & $0(0 \%)$ & NOR & $0(0 \%)$ & NOR & $10(100 \%)$ \\
& TE & $2(20 \%)$ & TE & $8(80 \%)$ & TE & $0(0 \%)$ \\
\hline
\end{tabular}

${ }^{*} \mathrm{n}=$ No. of isolates subjected to antibiotic profile, $\mathrm{S}=$ Streptomycin, GEN $=$ Gentamicin, $\mathrm{CIP}=\mathrm{Ciprofloxacin}, \mathrm{NOR}=$ Norfloxacin, $\mathrm{TE}=$ Tetracycline.

Table 4. Overall percentages (\%) of antibiogram profiles of isolated E. coli from collected samples

\begin{tabular}{lccc}
\hline Antibiotics & Resistant & Intermediate & Sensitive \\
\hline Streptomycin & $5(25 \%)$ & $0(0 \%)$ & $15(75 \%)$ \\
Gentamycin & $0(0 \%)$ & $7(35 \%)$ & $13(65 \%)$ \\
Ciprofloxacin & $0(0 \%)$ & $0(0 \%)$ & $20(100 \%)$ \\
Norfloxacin & $0(0 \%)$ & $0(0 \%)$ & $20(100 \%)$ \\
Tetracycline & $2(10 \%)$ & $18(90 \%)$ & $0(0 \%)$ \\
\hline
\end{tabular}

The findings of this research work would certainly help the veterinary practitioners to select the proper antibiotics against diarrhoea in goats of Bangladesh, particularly in the study area. If the prescribers prescribe suitable antibiotics against diarrhoea in goats then it would be possible to overcome the multi-drug resistant problem of bacteria, otherwise successful antibiotic therapy against diarrhoea in goats would not be possible. 


\section{F. Begum and others}

\section{CONCLUSIONS}

E. coli were successfully isolated from healthy and diarrheic goat and confirmed by PCR. Overall occurrence of E. coli was $70 \%$. Based on the present study, it may be concluded that use of ciprofloxacin and norfloxacin will be of first choice of treatment against $E$. coli infection in goats located at the study area. Findings of this study have suggested that multidrug resistant $E$. coli isolated from goat might be an important concern for veterinary practitioners. Nevertheless, more studies are needed to clearly understand the genomic diversity in $E$. coli as well as molecular mechanisms of virulence and development of antimicrobial resistance.

\section{ACKNOWLEDGEMENTS}

The authors are grateful to the Ministry of Science and Technology, Government of the People's Republic of Bangladesh for financial support.

\section{REFERENCES}

1. Abdullah ASM, Khan MSR, Alam M, Haq F and Hassan J (2010). Isolation and Molecular Characterization of Escherichia coli from goat of apparently healthy and clinical cases. Bangladesh Journal of Microbiology 27: 14-17.

2. Banglapedia (2015). Livestock animal of Bangladesh. http://en.banglapedia.org/index.php?title=Livestock.

3. Bauer A, Kirby W, Sherris JC and Turck M (1966). Antibiotic susceptibility testing by a standardized single disk method. American Journal of Clinical Pathology 45: 493.

4. CLSI (2012). Performance Standards for Antimicrobial Disk Susceptibility Tests; Approved Standard-Eleventh Edition. CLSI document M02-A11. Wayne, PA: Clinical and Laboratory Standards Institute.

5. Cowan ST (1985). Cowan and Steel's Manual for Identification of Medical Bacteria. 2nd edn., Cambridge University Press, Cambridge, London. pp. 138-139.

6. Gupta MD, DAS A, Islam MZ and Biswas PK (2016). Prevalence of sorbitol non-fermenting Shiga toxinproducing Escherichia coli in Black Bengal goats on smallholdings. Epidemiology and Infection 8: 1-8.

7. Islam K, Ahad A, Barua M, Islam A, Chakma S, Dorji C, Uddin MA, Islam A and Ahasan ASML (2016). Isolation and epidemiology of multidrug resistant Escherichia coli from goats in Cox's Bazar, Bangladesh. Journal of Advanced Veterinary and Animal Research 3:166-172.

8. Islam MS, Mondol AS, Boer E, Beumer RR, Zwietering MH, Talukder KA and Heuvelink AE (2008). Prevalence and genetic characterization of shiga toxin-producing Escherichia coli isolates from slaughtered animals in Bangladesh. Applied and Environmental Microbiology 74: 175414-5421.

9. Marshall B, Petrowski D and Levy SB (1990). Inter and intra species spread of Escherichia coli in a farm environment in the absence of antibiotic usage. National Academy, USA. 87: 6609-6613.

10. Medici D, Croci L, Delibato E, Pasquale SD, Filetici E and Toti L (2003). Evaluation of DNA extraction methods for use in combination with SYBR Green I Real-Time PCR to detect Salmonella enterica serotype enteritidis in poultry. Applied and Environmental Microbiology 69: 3456-3461.

11. Nazir KHMNH, Rahman MB, Nasiruddin KM, Akhtar F, Khan MFR and Islam MS (2005). Antibiotic sensitivity of Escherichia coli isolated from water and its relation with plasmid profile analysis. Pakistan Journal of Biological Sciences 8: 1610-1613.

12. Radostits OM, Gay CC, Blood DC and Hinchcliff KW (2000).Veterinary Medicine: A Textbook of Disease of Cattle, Sheep, Pigs, Goats and Horses. $6^{\text {th }}$ edn.,WB Saunders, New York, USA. pp. 467.

13. Schippa S, Iebba V, Barbato M, Nardo GD, Totino V, Checchi MP, Longhi C, Maiella G, Cucchiara S and Conte MP (2010). A distinctive microbial signature in celiac pediatric patients. BMC Microbiology 10: 175-185. 